\title{
Suturing Technique to Promote Graft Attachment in Challenging Cases of Descemet Stripping Endothelial Keratoplasty
}

\author{
Miltiadis Papathanassiou, Lamprini Papaioannou \\ Cornea Clinic, 2nd Ophthalmology Department, Attikon University Hospital, Athens, Greece \\ Email: papathanassiou1@gmail.com
}

Received 16 June 2015; accepted 11 August 2015; published 14 August 2015

Copyright (C) 2015 by authors and Scientific Research Publishing Inc.

This work is licensed under the Creative Commons Attribution International License (CC BY). http://creativecommons.org/licenses/by/4.0/

(c) (i) Open Access

\begin{abstract}
Aims: To describe a technique that uses a transcorneal fixation suture for graft attachment in endothelial keratoplasty in high-risk for graft dislocation eyes. Materials and Methods: Case series included 12 eyes of 12 patients who underwent Descemet Stripping Automated Endothelial Keratoplasty (DSAEK) in the presence of high risk for graft dislocation factors. We describe a surgical technique that uses a transcorneal fixation suture to compress the donor graft onto the back surface of the recipient cornea. Outcome measures included intraoperative and postoperative complications, graft attachment and clarity and endothelial cell count at a 12 months follow-up period. Results: No intraoperative complications were noted and 11 grafts remained attached and clear with no suture related complications at a 12-month follow-up period. Partial peripheral graft detachment due to suture related graft folds, accompanied by mild corneal edema was noticed in one patient postoperatively. Reattachment and edema resolution occurred spontaneously after suture removal. The mean endothelial cell loss was $38.21 \%$ at 12 months. Conclusions: Temporary transcorneal fixation suture can be helpful in preventing graft detachment in eyes with high risk for graft dislocation.
\end{abstract}

\section{Keywords}

Descemet Stripping Endothelial Keratoplasty, Endothelial Graft Detachment, Transcorneal Fixation Suture

\section{Introduction}

Descemet Stripping Automated Endothelial Keratoplasty (DSAEK) is a form of corneal transplantation in which

How to cite this paper: Papathanassiou, M. and Papaioannou, L. (2015) Suturing Technique to Promote Graft Attachment in Challenging Cases of Descemet Stripping Endothelial Keratoplasty. Open Journal of Ophthalmology, 5, 124-129. 
a donor posterior corneal button, including donor corneal endothelium, Descemet's membrane, and posterior corneal stroma, is used for selective replacement of corneal endothelium in conditions characterized by corneal endothelial dysfunction. It is considered a safe technique that results in early visual recovery and refractive and tectonic stability [1]. Graft dislocation is the most common post-operative complication of DSAEK [1] [2]. Dislocations may represent either fluid in the interface of an otherwise well-positioned graft or complete dislocation into the anterior chamber and are typically evident within the first postoperative week, although reports of late dislocations exist [3]. Postoperative hypotony, maintained viscoelastic material in the interface, incomplete air fill, donor disc placed upside down, delayed endothelial pump function, primary graft failure and eye rubbing are considered as intraoperative and postoperative possible causes of dislocation [4] [5]. The presence of glaucoma drainage devices and minimal or absent iris-lens diaphragm, including aphakia, are risk factors for higher rates of graft dislocation as they can result in loss of tamponading air [6]-[9]. The presence of an anterior chamber intraocular lens (AC IOL) can also make the filling of the anterior chamber with air and maintenance of the air bubble difficult, while it also interferes with the surgical handling of the graft [10]-[13]. Prior failed penetrating keratoplasty (PK), especially in patients with irregular internal PK wound and graft-to-host disparity, can also make the DSAEK procedure challenging [14]-[16]. We report a case series of 12 patients who undergo DSAEK in the presence of high risk for graft detachment factors. We describe a technique that uses a transcorneal fixation suture to compress the donor graft onto the back surface of the recipient cornea, promoting endothelial graft attachment.

\section{Materials and Methods}

We present a case series including 12 eyes of 12 patients, 9 male and 3 female, whounderwent DSAEK in the presence of high risk for graft dislocation factors. Five patients underwent DSAEK under prior failed PK with irregular internal PK wound, 2 of them had AC IOL and 1 of them had also undergone primary failed DSAEK. Two patients had endothelial decompensation in the presence of a glaucoma drainage device and 5 patients had pseudophakic bullous keratopathy in the presence of an AC IOL. Demographic and clinical patient data are summarized in Table 1. All procedures were uneventful, performed by a single surgeon. Outcome measures

Table 1. Demographic and clinical data of patients.

\begin{tabular}{|c|c|c|c|c|c|c|}
\hline Patient & Age & Sex & Indication for keratoplasty & Risk factors & $\begin{array}{l}\text { Preoperative } \\
\text { BCVA }\end{array}$ & $\begin{array}{c}\text { Postoperative } \\
\text { BCVA (at } 12 \\
\text { months) }\end{array}$ \\
\hline 1 & 71 & M & Endothelialde compensation & Ahmed valve & $20 / 160$ & $20 / 50$ \\
\hline 2 & 68 & M & $\begin{array}{l}\text { Fuchs' endothelial dystrophy, primary } \\
\text { failed DSEK }\end{array}$ & Failed PK & $20 / 200$ & $20 / 50$ \\
\hline 3 & 79 & $\mathrm{~F}$ & Pseudophakic bullous keratopathy & Failed PK & $20 / 400$ & $20 / 50$ \\
\hline 4 & 87 & M & Pseudophakic bullous keratopathy & $\begin{array}{l}\text { AC-IOL with large anomalous } \\
\text { pupil (> } 8 \mathrm{~mm} \text {, larger than the } \\
\text { AC-IOL body) }\end{array}$ & $20 / 400$ & $20 / 40$ \\
\hline 5 & 80 & M & Pseudophakic bullous keratopathy & $\begin{array}{l}\text { Failed PK, AC-IOL, broad } \\
\text { peripheral iridectomy }\end{array}$ & $20 / 200$ & $20 / 32$ \\
\hline 6 & 69 & $\mathrm{~F}$ & Pseudophakic bullous keratopathy & AC-IOL & $20 / 160$ & $20 / 25$ \\
\hline 7 & 72 & M & Endothelialde compensation & Ahmed valve & $20 / 200$ & $20 / 40$ \\
\hline 8 & 76 & M & Pseudophakic bullous keratopathy & Failed PK, AC-IOL & $20 / 400$ & $20 / 40$ \\
\hline 9 & 65 & M & Pseudophakic bullous keratopathy & AC-IOL & $20 / 100$ & $20 / 25$ \\
\hline 10 & 80 & $\mathrm{~F}$ & Pseudophakic bullous keratopathy & AC-IOL & $20 / 100$ & 20/32 \\
\hline 11 & 79 & M & Pseudophakic bullous keratopathy & Failed PK & $20 / 200$ & $20 / 50$ \\
\hline 12 & 75 & M & Pseudophakic bullous keratopathy & AC-IOL & $20 / 160$ & $20 / 50$ \\
\hline
\end{tabular}

BCVA = best corrected visual acuity, $\mathrm{M}=$ male, $\mathrm{F}=$ female, $\mathrm{PK}=$ penetrating keratoplasty, DSEK = descemet stripping endothelial keratoplasty, AC-IOL = anterior chamber intraocular lens 
included intraoperative and postoperative complications, graft attachment and clarity and endothelial cell count at a 12 months follow-up period.

\section{Surgical Technique}

Descemet stripping was performed aiming for a diameter of $8.5 \mathrm{~mm}$, using an $8.5 \mathrm{~mm}$ circular marker dipped in trypan blue. An anterior chamber maintainer was placed at the 6 o'clock position. Precut endothelial grafts were used in all 12 cases ( $1 \mathrm{~mm}$ larger than previous failed PK graft in 5 cases). Folded donor disc was inserted through a $4.5 \mathrm{~mm}$ incision using Busin glide. The graft was allowed to unfold spontaneously and the anterior chamber maintainer was removed. Gentle external cornea tapping resulted in centration of the graft. On correct positioning, air was injected into the anterior chamber (AC) to attach the graft onto the stromal bed. After all incisions being sutured airtight with 10.0 nylon sutures, air was injected with a 30 -gauge needle filling the AC with air. Afterwards, 1 to 2 transcorneal sutures were used to stabilize the graft. 10.0 nylon sutures were placed full-thickness passing from the peripheral cornea inwards, and then passing through the donor tissue, and through the full thickness of the cornea stroma. Knots were buried, rotating the sutures to the periphery away from the graft. Opposite rotation could lead to graft folds. After the knots being buried, the AC was refilled with air for 10 minutes. Thereafter the air was reduced, leaving a 50\% air bubble in the AC. The ensuing steps of the technique are illustrated in Figure 1. Sutures were removed four weeks later.

\section{Results}

There were no intraoperative complications. 11 grafts (91.7\%) remained attached and clear at a 12-months follow-up period (Figure 2, Figure 3). Partial peripheral graft detachment due to suture related graft folds, accompanied by mild corneal edema, was noticed in one patient postoperatively. Reattachment and edema resolution occurred spontaneously after suture removal (Figure 4). No further suture-related complications, such as endophtalmitis and epithelial ingrowth were noted. Mean best corrected visual acuity (BCVA) was 20/40. Mean endothelial cell count measured by specular microscope (EM-3000, Tomey, Erlangen, Germany) was 1569 cells $/ \mathrm{mm}^{2}$ at 12 months postoperatively, representing a mean endothelial cell loss of $38.21 \%$ compared with post-cut cell count (Table 2).

\section{Discussion}

The presence of AC IOL, prior failed PK, minimal or absent iris-lens diaphragm and glaucoma drainage devices have been examined as risk factors for higher rates of graft dislocation. In cases where the AC IOL is not the cause of endothelial decompensation and the depth of the anterior chamber is adequate, an intraocular lens exchange is not required [10]-[12]. As reported, DSAEK in the presence of a well-centered AC IOL and AC IOL-to-endothelium depth greater than $3 \mathrm{~mm}$, resulted in no significant difference in cell loss compared with DSAEK cases in the presence of a posterior chamber intraocular lens [10] [11]. In such cases, the DSAEK procedure becomes more challenging, as it is difficult for an adequate air bubble to remain in the anterior chamber without escaping into the vitreous cavity, while the presence of an intraocular lens in the anterior chamber interferes with surgical handlings.

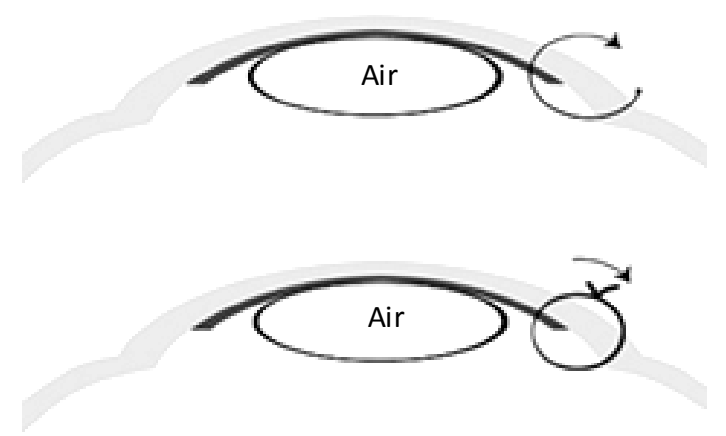

Figure 1. Fixation suture technique: 10.0 nylon sutures are placed full-thickness passing from the peripheral cornea towards the center, through the donor disc and the corneal stroma. Knots are buried, rotating the sutures to the periphery away from the graft. 

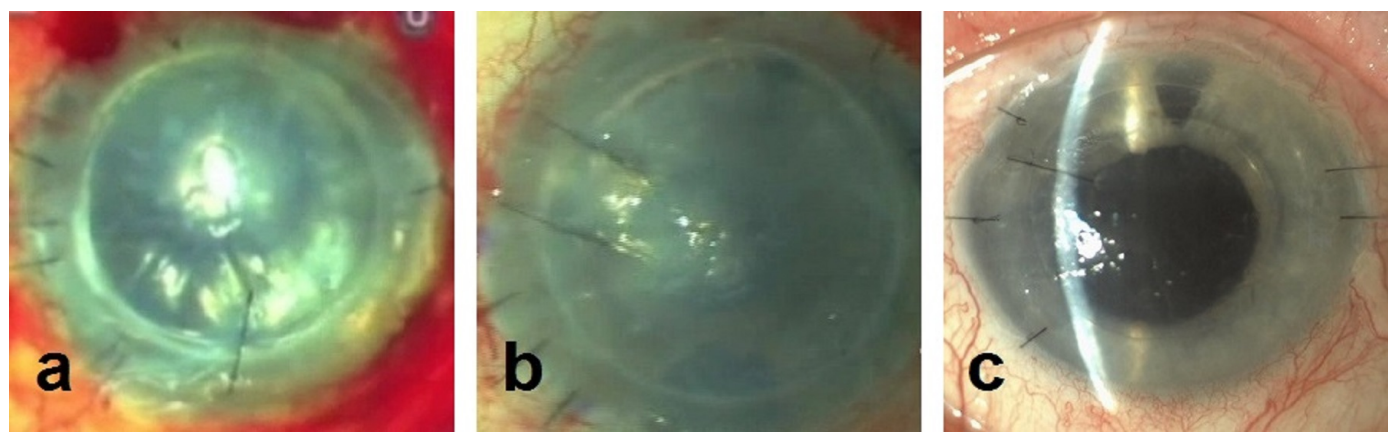

Figure 2. Intraoperative (a) (b) and postoperative (c) figures of transcorneal fixation suture in high risk patients. Two sutures were used to offer additional attachment in a patient with a prior failed PK and abnormal internal PK wound (b).
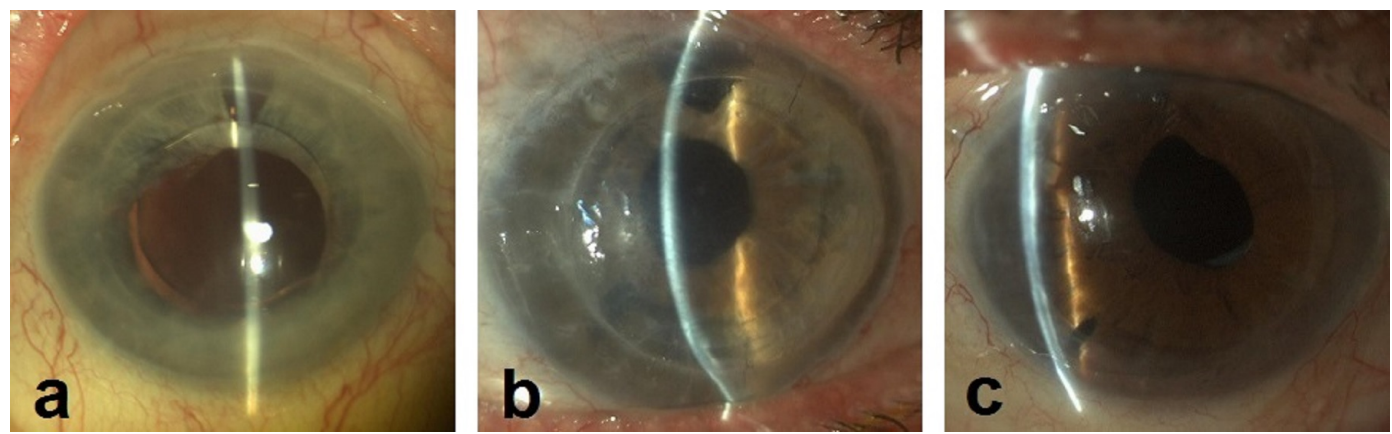

Figure 3. Attached and clear grafts at a 12-month follow-up period in a patient with AC-IOL and a large anomalous pupil (a), a case of prior failed PK in the presence of AC-IOL (b) and a patient with glaucoma drainage device (c).
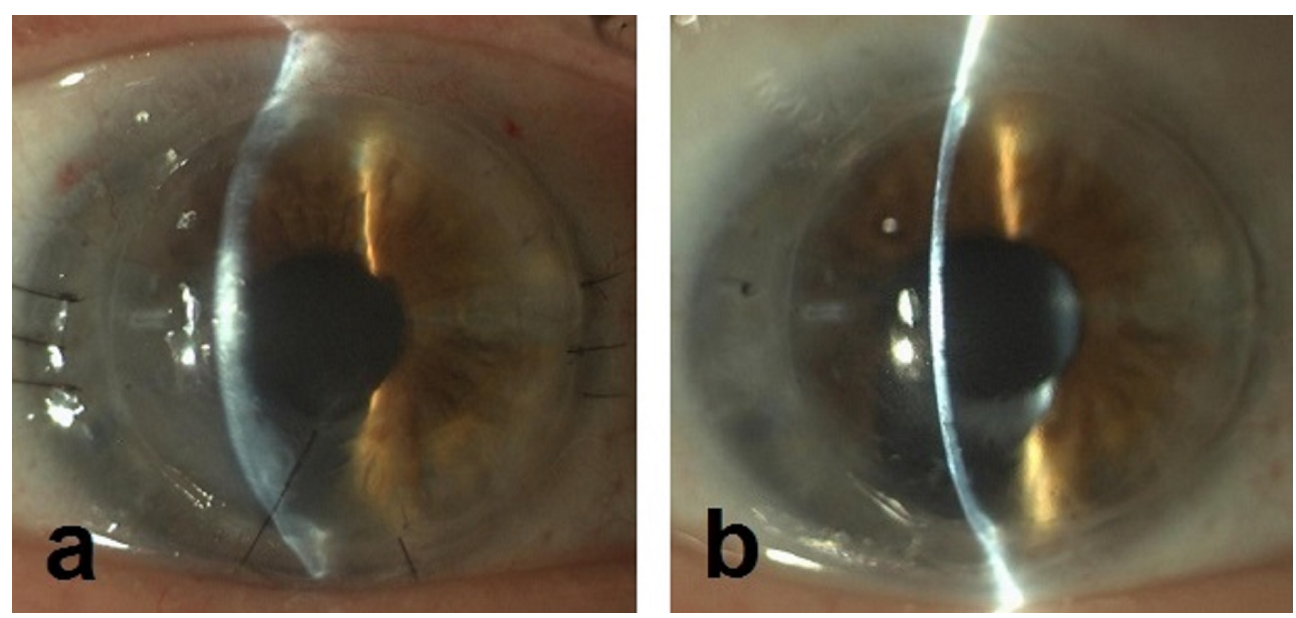

Figure 4. Postoperative partial peripheral graft detachment due to graft folds, accompanied by mild corneal edema in a second (redo) DSEK case with a history of failed DSEK and failed PK (a). Spontaneous reattachment and edema resolution after suture removal (b).

Minimal or absent lens-iris diaphragm and glaucoma drainage devices also result in difficulty for an adequate air bubble to be maintained in the anterior chamber, while the risk of posterior graft dislocation into the vitreous cavity in aphakic eyes is high [6]-[9]. Prior failed PK represents an indication for DSAEK procedure in eyes with an acceptable topography and refractive outcome before PK graft failure [15]. Endothelial graft diameter and irregular internal PK wound in prior failed PK have also been examined as risk factors for graft dislocation. Clements et al. have reported higher rates of graft dislocation in cases where endothelial graft diameter was smaller than the previous PK graft, as well as in cases with glaucoma drainage devices [14]. This result is consistent with Anshu et al. series of 60 patients, where low dislocation rates (6.6\%) were noticed using 
Table 2. Endothelial cell count.

\begin{tabular}{ccc}
\hline Patient & Post-cut cell count/mm² & 12 Months postoperatively \\
\hline 1 & 2511 & 1622 \\
2 & 3012 & 1731 \\
3 & 2600 & 1604 \\
4 & 2508 & 1539 \\
5 & 2514 & 1562 \\
6 & 2410 & 1451 \\
7 & 2462 & 1511 \\
8 & 2471 & 1506 \\
9 & 2511 & 1553 \\
10 & 2502 & 1547 \\
11 & 2453 & 1617 \\
12 & 2517 & 1585 \\
\hline
\end{tabular}

oversized grafts [15]. On the other hand Straiko et al. reported similar rates of dislocation (5.9\%) using graft diameters less than or equal to the PK diameter in 17 cases [16].

Suture fixation has already been reported as an alternative management of dislocated grafts after the first reposition, aiming to engage the peripheral edge of the donor tissue and support it in place until the endothelial pump function takes over [17] [18]. "Preventive" transcorneal suturing as part of the insertion technique has also been reported [8] [19]. Patel et al. described a technique that uses an anchoring suture as part of the insertion technique in eyes with minimal or absent iris-lens diaphragm. This technique aims in safe delivery and fixation of donor disk while facilitating the management of graft detachment by rebubbling, as the graft remains attached at sutured edge [8]. The use of one transcorneal sutures either as a part of the insertion technique or as a separated suture has also been described by Elderkin et al. in eyes with AC IOL [12]. In both series one single suture was used to hold the graft in place preventing complete detachment, while partial detachment occurred in 2 out of 13 cases in Patel series and in 1 out of 11 cases in Elderkin series.

We propose the use of a full-thickness, temporary, "preventive", transcorneal suture as part of the DSAEK procedure which can fixate the graft at the posterior surface of the cornea preventing graft dislocation in high risk cases. We believe that the use of 2 transcorneal sutures when needed offers additional attachment and eliminates even partial detachment. Although more sutures could result in higher rates of suture related complications, prevention of dislocation is considered a safer approach by the authors, as reposition and rebubbling is associated with increased endothelial cell loss [4] [20]. In our series no significant suture related complication, such as endophthalmitis and epithelial ingrowth due to the full-thickness suturing was noticed. A limitation of this study is the small number of participants, but the encouraging results could suggest the use of this technique and the assessment of its efficacy in larger series.

\section{Conclusion}

In summary, temporary transcorneal fixation sutures as a part of the primary DSAEK procedure can be helpful in high risk for graft dislocation eyes. Although our series is small, results are encouraging, as all grafts remain attached and clear, while no significant complication is noticed.

\section{References}

[1] Lee, W.B., Jacobs, D.S., Mush, D.C., Kaufman, S.C., Reinhart, W.J. and Shtein, R.M. (2009) Descemet’s Stripping Endothelial Keratoplasty: Safety and Outcomes: A Report by the American Academy of Ophthalmology. Ophthalmology, 116, 1818-1830. http://dx.doi.org/10.1016/j.ophtha.2009.06.021

[2] Suh, L., Yoo, S., Deobhakta, A., Donaldson, K., Alfonso, E., Culbertson, W., et al. (2008) Complications of Descemet’s Stripping with Automated Endothelial Keratoplasty: Survey of 118 Eyes at One Institute. Ophthalmology, 115, 
1517-1524. http://dx.doi.org/10.1016/j.ophtha.2008.01.024

[3] Busin, M. and Bhatt, M.R. (2008) Late Detachment of Donor Graft after Descemet Stripping Automated Endothelial Keratoplasty. Journal of Cataract \& Refractive Surgery, 34, 159-160. http://dx.doi.org/10.1016/j.jcrs.2007.08.027

[4] Terry, M.A. and Ousley, P.J. (2006) Deep Lamellar Endothelial Keratoplasty: Early Complications and Their Management. Cornea, 25, 37-43. http://dx.doi.org/10.1097/01.ico.0000164781.33538.b6

[5] Price Jr., F.W. and Price, M.O. (2006) Descemet’s Stripping with Endothelial Keratoplasty in 200 Eyes: Early Challenges and Techniques to Enhance Donor Adherence. Journal of Cataract \& Refractive Surgery, 32, 411-418. http://dx.doi.org/10.1016/j.jcrs.2005.12.078

[6] Kim, P., Amiran, M.D., Lichtinger, A., Yeung, S.N., Slomovic, A.R. and Rootman, D.S. (2012) Outcomes of Descemet Stripping Automated Endothelial Keratoplasty in Patients with Previous Glaucoma Drainage Device Insertion. Cornea, 31, 172-175. http://dx.doi.org/10.1097/ICO.0b013e318224820a

[7] Suh, L.H., Kymionis, G., Culbertson, W.W., O’Brien, T.P. and Yoo, S.H. (2008) Descemet’s Stripping with Endothelial Keratoplasty in Aphakic Eyes. Archives of Ophthalmology, 126, 268-270. http://dx.doi.org/10.1001/archophthalmol.2007.32

[8] Patel, A.K., Luccarelli, S., Ponzin, D. and Busin, M. (2011) Transcorneal Suture Fixation of Posterior Lamellar Grafts in Eyes With Minimal or Absent Iris-Lens Diaphragm. American Journal of Ophthalmology, 151, 460-464. http://dx.doi.org/10.1016/j.ajo.2010.08.043

[9] Price, M.O., Price Jr., F.W. and Trespalacios, R. (2007) Endothelial Keratoplasty Technique for Aniridicaphakic Eyes. Journal of Cataract \& Refractive Surgery, 33, 376-379. http://dx.doi.org/10.1016/j.jcrs.2006.10.052

[10] Esquenazi, S., Schechter, B.A. and Esquenazi, K. (2011) Endothelial Survival after Descemet-Stripping Automated Endothelial Keratoplasty in Eyes with Retained Anterior Chamber Intraocular Lenses: Two-Year Follow-Up. Journal of Cataract \& Refractive Surgery, 37, 714-719. http://dx.doi.org/10.1016/j.jcrs.2010.10.054

[11] Esquenazi, S. (2009) Safety of DSAEK in Pseudophakic Eyes with Anterior Chamber Lenses and Fuchs Endothelial Dystrophy. British Journal of Ophthalmology, 93, 558-559. http://dx.doi.org/10.1136/bjo.2008.154914

[12] Elderkin, S., Tu, E., Sugar, J., Reddy, S., Kadakia, A., Ramaswamy, R. and Djalilian, A. (2010) Outcome of Descemet Stripping Automated Endothelial Keratoplasty in Patients with an Anterior Chamber Intraocular Lens. Cornea, 29, 12731277. http://dx.doi.org/10.1097/ICO.0b013e3181d00a5e

[13] Groat, B., Ying, M.S., Vroman, D.T., Fernandez de Castro, L.E. (2007) Descemet-Stripping Automated Endothelial Keratoplasty Technique in Patients with Anterior Chamber Intraocular Lenses-Video Report. British Journal of Ophthalmology, 91, 714. http://dx.doi.org/10.1136/bjo.2007.121343

[14] Clements, J.L., Bouchard, C.S., Lee, W.B., Dunn, S.P., Mannis, M.J., Reidy, J., et al. (2011) Retrospective Review of Graft Dislocation Rate Associated with Descemet Stripping Automated Endothelia Keratoplasty after Primary Failed Penetrating Keratoplasty. Cornea, 30, 414-418. http://dx.doi.org/10.1097/ICO.0b013e3181f7f163

[15] Anshu, A., Price, M.O. and Price, F.W. (2011) Descemet’s Stripping Endothelial Keratoplasty under Failed Keratoplasty: Visual Rehabilitation and Graft Survival Rate. Ophthalmology, 118, 2155-2160. http://dx.doi.org/10.1016/j.ophtha.2011.04.032

[16] Straiko, M.D., Terry, M.A. and Shamie, N. (2011) Descemet Stripping Endothelial Keratoplasty under Failed Penetrating Keratoplasty: A Surgical Strategy to Minimize Complications. American Journal of Ophthalmology, 151, 233237. http://dx.doi.org/10.1016/j.ajo.2010.08.017

[17] Anandan, M. and Leyland, M. (2008) Suture Fixation of Dislocated Endothelial Grafts. Eye, 22, 718-721. http://dx.doi.org/10.1038/sj.eye.6703000

[18] Wu, W.K., Wong, V. and Chi, S. (2011) Graft Suturing for Lenticule Dislocation after Descemet Stripping Automated Endothelial Keratoplasty. Journal of Ophthalmic \& Vision Research, 6, 131-135

[19] Macsai, M.S. and Kara-Jose, A.C. (2007) Suture Technique for Descemet Stripping and Endothelial Keratoplasty. Cornea, 26, 1123-1126. http://dx.doi.org/10.1097/ICO.0b013e318124a443

[20] Price, M.O. and Price, F.W. (2008) Endothelial Cell Loss after Descemet Stripping with Endothelial keratoplasty: Influencing Factors and 2-Year Trend. Ophthalmology, 115, 857-865. http://dx.doi.org/10.1016/j.ophtha.2007.06.033 